\title{
Adaptive coping strategies and mechanisms used by students to combat pandemic stress
}

Florentina Mogonea, Florentin Remus Mogonea 


\title{
Adaptive coping strategies and mechanisms used by students to combat pandemic stress
}

\author{
Florentina Mogonea ${ }^{a^{*}}$, Florentin Remus Mogonea ${ }^{b}$ \\ ${ }^{a}$ University of Craiova, 13, A.I. Cuza Street, Craiova, 200585, Romania \\ ${ }^{b}$ University of Craiova, 13, A.I. Cuza Street, Craiova, 200585, Romania \\ *Corresponding author: mogoneaf@yahoo.com
}

\section{Abstract}

\section{Keywords:}

stress; adaptive coping strategies and mechanisms; pandemic period; lockdown status; online activity.
The present study aims to investigate the adaptive coping strategies and mechanisms of students-future teachers in combating the stress caused by the pandemic. The subjects of the investigation were 58 master students, from the Faculty of Letters, University of Craiova, who are also studying to become teachers. The tool we used was an opinion questionnaire, through which we investigated the opinion of the subjects on the stated issue and we inventoried the ways they used to manage stress. We aimed to identify the most frequent emotional reactions of the students to the effects generated by the measures and restrictions imposed during the pandemic period, which the students critically analyzed, from the perspective of the caused shortcomings, but also the offered opportunities. We also investigated the students' opinion about the specifics of the teaching activity, carried out online, compared to the one face to face. The results obtained from the application of the instrument confirmed the research hypotheses.

\section{Zusammenfasung}

\section{Schlüsselworte:}

stress; adaptive

bewältigungsstrategien und mechanismen; pandemiezeit; abriegelungszustand; onlineAktivität.
In der vorliegenden Studie sollen die adaptiven Bewältigungsstrategien und -mechanismen von Lehramtsstudenten bei der Bewältigung von Pandemiestress untersucht werden. Bei den untersuchten Personen handelte es sich um 58 Masterstudenten der Fakultät für Literatur der Universität Craiova, die sich gleichzeitig auf den Lehrerberuf vorbereiten. Das verwendete Instrument war ein Meinungsfragebogen, mit dem wir die Meinung der Probanden zu dem Problem untersuchten und die von ihnen verwendeten Stressbewältigungsmethoden erfassten. Ziel war es, die häufigsten emotionalen Reaktionen der Studenten auf die Auswirkungen der Maßnahmen und Einschränkungen während der Pandemie zu ermitteln, die die Studenten unter dem Gesichtspunkt der Unannehmlichkeiten und der gebotenen Möglichkeiten kritisch analysierten. Wir untersuchten auch die Meinung der Studierenden zu den Besonderheiten der Lehrtätigkeit, die online im Vergleich zu persönlichem Unterricht durchgeführt wird. Die durch die Anwendung des Instruments erzielten Ergebnisse bestätigten die Forschungshypothesen.

\section{Introduction}

The pandemic period, caused by the SARS-COV2 virus, has caused numerous effects, changes, both socially and individually. Society, as a whole, and each subsystem, has felt more or less these effects and had to find solutions, ways to overcome the difficulties. The medical problems, the threat of health, the need to comply with the imposed rules and restrictions can be considered as significant stressors on the population. Each individual has tried to find their own self-defense mechanisms.

The education system has also been affected by the effects of the pandemic. The school had to find solutions to allow the continuation of the fundamental activities, teaching, learning and assessment, thus, facing many difficulties related to the necessary infrastructure, the digital skills of both teachers and students, the need to adapt the didactic strategies used in face-to-face activities to the specifics of online education, to reduce the gap between the backgrounds of the beneficiaries (rural, urban), to provide solutions to the families and children with no material possibilities, to ensure digital literacy etc.

Beyond all these problems of the system as a whole, we cannot ignore the effects of this period on an individual level, as well as the ways in which students, teachers and school staff alike can be helped to get through this difficult period more easily. Perhaps for all the categories involved, the pandemic period has been a threat, a challenge, both due to the restrictions imposed, the stress caused by isolation, distancing, fear of illness and due to the need to adapt, in a very short time, to the specifics of online activities. 
We are capturing these aspects in the context of academic activity, respectively in the field of the initial training of the students-future teachers. We are interested in their perception of the pandemic period, as well as the ways in which they managed to handle the stress caused by it. Both the stressors and the ways to diminish/ eliminate their effects specific, in general, to academic learning, acquire, in the new context, an increase in intensity and an increase in the frequency of manifestation.

\section{Stress and the coping mechanisms}

The concept of stress is, as difficult to define, as rich in meanings, semantic nuances. In trying to define stress, most people tend to describe how they feel or react to a stressful situation rather than saying what stress really is. Therefore, stress is perceived differently by different people. For some, stress represents the events or situations that cause them tension, pressure or negative emotions, such as anxiety or anger. For others, it is the answer to these situations (Baqutayan, 2015, pp. 479-480).

According to the first definition of this concept, offered by the "father" of stress, Hans Selye (apud Fink, 2017, p. 4), we can consider stress as the nonspecific response of the body to any request.

From a psychological perspective, stress can be considered a mental state, felt as pressure or tension (Shahsavarani, Abadi, Kalkhoran, 2015, p. 230). The authors cited above state that it is desirable to have a low level of stress, which does not affect our performance in the activity. They also consider that, beyond the negative, well-known hypothesis of stress, one can also speak of a positive stress, which can be an important factor of motivation, adaptation and reaction to the environment. Otherwise, in the variant of a high level of stress, it can have biological, psychological, social consequences (Shahsavarani, Abadi, Kalkhoran, 2015, p. 230).

Stress can be caused by many and various factors or causes. Mazo (2015) makes a list of stressors that act on students, influencing their activity or academic performance. Here are some of them: tests, examinations; work tasks/ homework; school projects; practical/ demonstrative activities; presentations, speeches; family problems; conflicts; sentimental problems, deceptions; responsibilities at home; long distance between school and home; the high expectations of the teachers; strict, rigid parents; poor health; school rules/ policy (Mazo, 2015, p. 75).
The effects of stress on the body are treated in numerous studies. The effects can be physiological, psychological, behavioral. Mazo (2015, p. 76) analyzes, in a research, some of the most common effects: insomnia; poor performance at school; irritability; headaches; fatigue; sadness, the feeling of loneliness; nervousness; low appetite; absenteeism; late performance of tasks, homework; feelings of insecurity; an attitude of rebellion, revolt, conflict.

Some authors (Al Dubai, Al Naggar, Al Shagga, Rampal, 2011) group stressors into academic factors, which are related to the school activity of the pupils or students and non-academic factors, which address social, family, financial issues.

These effects are amplified and intensified, in the context of the pandemic period, by the conditions and restrictions imposed by it. Depression and anxiety are considered to be among the most common symptoms, which has led to an increased interest from the researchers (Mariani et al., 2020; Kecoevic, Basch, Sullivan, Davi, 2020).

In crises, stressful events, each person changes, regulates their own emotions, behaviors, way of thinking, through a voluntary effort, which can be considered as a coping strategy (Compas et al., 1999, apud Liang , Delvecchio, Buratta, \& Mazzeschi, 2020).

Regarding the ways of stress management, specialized literature presents a series of mechanisms, focused either on the problem, on the situation or on the emotional dimension of the approach to the situation (Lazarus et al., 1986, Carver et al., 1989, apud Baqutayan, 2015, pp. 482). Following the research, the author proposes a list of strategies or mechanisms, grouping them into the two categories mentioned (Table 1).

Table 1. Stress management mechanisms

\begin{tabular}{|c|c|c|}
\hline & $\begin{array}{l}\text { Situation/ problem centered } \\
\text { mechanisms }\end{array}$ & $\begin{array}{l}\text { Mechanisms focused on the emotional } \\
\text { state }\end{array}$ \\
\hline 1 & Active coping & $\begin{array}{l}\text { Seeking social support for emotional } \\
\text { reasons }\end{array}$ \\
\hline 2 & Planning & Pasitive геinterpretation and development \\
\hline 3 & Retention coping & Acceptance \\
\hline 4 & $\begin{array}{l}\text { Seeking social support for } \\
\text { instrumental reasons }\end{array}$ & Denial \\
\hline 5 & Behavioral non-intervention & Refugee in religion \\
\hline 6 & & Focusing on emations and expressing them \\
\hline 7 & & Mental non-intervention \\
\hline 8 & & Humour \\
\hline 马 & & Alcohol/ drug use \\
\hline
\end{tabular}

Source: Baqutayan, 2015, p. 483 
In agreement with Mazo (2015, p. 77), we are mentioning other ways used to control stress: meetings with friends; seeking advice from a friend or classmate; watching TV shows or movies; computer use; emotion control; involvement in activities that keep him/ her busy; music; prayers; asking for help from parents; concealment, masking reactions or emotions; seeking the help of a school counselor or teacher. Unfortunately, some people use alcohol or drugs in stressful situations in order to reduce the emotional discomfort caused by the event or stressor.

Some authors (Chandra, 2021) mention emotional intelligence as a coping mechanism/ strategy of academic stress, in the context of the pandemic.

Let us list some tips/ recommendations that can support students in managing the stress caused by online activities (after Field, 2020, pp. 8-11):

- Ask the students about tools and platforms!

- Involve the students in class leadership!

- Favor asynchronous approaches!

- Use affordable technologies!

- Temper your expectations!

- Share your own experiences!

- Provide support and resources!

- Create opportunities for the students to process information!

- Don't forget about students with disabilities!

- Take care of yourself, while also providing a role model for the students!

The American Psychological Association (2020, pp. 1-2) recommends several ways to control pandemic stress:

- Practice self-care;

- Find ways to focus;

- Seek out social support;

- Help others cope;

- Find ways to manage disappointment;

- Limit your media consumption;

- Focus on things you can control.

Most of the time, stress management can be achieved through one's own self-control efforts or through self-imposed activities, which could diminish the state of emotional discomfort. In some situations, however, the people in question may seek the support of a specialist (counselor, psychologist, psychiatrist). The difficulty of controlling the effects of stress may be greater in children and adolescents, amid poor selfcontrol. The support of the family, of the teachers must be substantial.

\section{The design of the research}

We conducted an empirical research, whose aim was to identify ways, mechanisms and

coping strategies used by the students to manage difficult situations during the pandemic.

The objectives we pursued were the following:

- Knowing the extent to which students consider that the pandemic period affected or influenced their school performance, learning activity in general;

- Identifying the most common emotional reactions of the students to the stress caused by the pandemic, as well as the extent to which they managed to handle stress;

- Highlighting the students' perceptions of the effects of online activities, compared to those performed in the face-to-face system;

- Inventory of the main shortcomings, disadvantages of the pandemic period, but also of its possible opportunities.

In accordance with these established intentionalities and in order to confirm them, we

established three working hypotheses, the truth of which was proven through the actions carried out with the target group:

1. The pandemic period and the conditions/ limitations imposed by it (distancing, isolation, danger of illness and awareness of its effects) caused significant emotional reactions among students.

2. There is a link between the emotional effects of the pandemic and the academic performance of the students.

3. The awareness of emotional states/ reactions, as effects of isolation or distancing favors the possibility of identifying adaptive mechanisms/ strategies for stress management.

In order to achieve the proposed finalities and to verify the true value of the hypotheses, we used a sample of subjects consisting of 58 master students from the first year, from different master programs within the Faculty of Letters, University of Craiova. In parallel they went through the psycho-pedagogical training program, in order to develop the skills necessary for the teaching profession. 


\section{The research methodology}

In order to conduct the investigation, we used the survey method based on the questionnaire, the tool being applied to students online, through Google forms.

\section{The description of the instrument}

The questionnaire realised by us included 12 items varied in terms of response, from those with closed answers (single choice-items 1, 2, 4, 9, 10, 11, 12 or multiple - item 3), to those with semi-closed (item 6) or open (items 7 and 8) answers. Through this variety of question formulation, we aimed to reduce the shortcomings that, as we know, each category of item has, as well as to cover the entire issue, so that the information provided by the subjects allows an overall assessment, as objective as possible, of their opinion on the issues pursued. In this respect, some items in the structure of the questionnaire were considered to be control items. We also asked the subjects for factual data, which we considered relevant for the research (specialization, age, sex, birth place)

\section{Results and discussions}

We are now presenting the results of the investigation, grouping them according to their contribution to the confirmation of the truth value of the three hypothetical statements formulated.

4a. In order to test the first hypothesis, which states that The pandemic period and the conditions/ limitations imposed by it (distancing, isolation, danger of illness and awareness of its effects) caused significant emotional reactions among students, we are presenting the results recorded in items 2, 3, 5 and 7 of the opinion questionnaire applied to master students.

For item no. 2, regarding the anxiety caused by the lockdown state, a third of the respondents (32.8\%) mentioned that this fact was largely achieved, and $31 \%$ - to an appropriate extent. $27.6 \%$ consider that the state of anxiety manifested itself to a small extent. Only 4 subjects $(6.9 \%)$ mentioned that the pandemic situation did not affect them, and $1.7 \%$ could not appreciate it (see figure no. 1):
Figure no. 1 . The opinion of the subjects on the anxiety caused by the lockdown

\section{The opinion of the subjects on the anxiety caused by the lockdown}

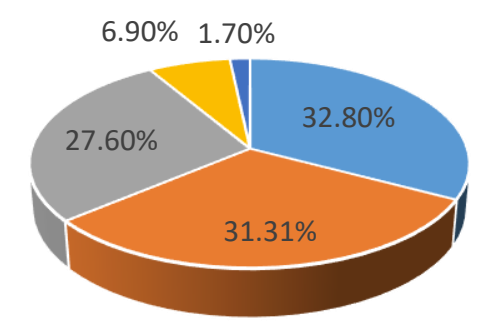

- a) To a large extent

- b) To an appropriate extent

- c) To a small extent

- d) Not at all

- e) I can't appreciate

Item 3 of the questionnaire asked the subjects to mention the most common emotional reactions caused by isolation, this being a multiple choice item. Figure no. 2 presents the answers of the subjects to this item.

Figure no. 2. The opinion of the subjects on the most common emotional reactions to isolation

\section{The opinion of the subjects on the most common emotional reactions to isolation}

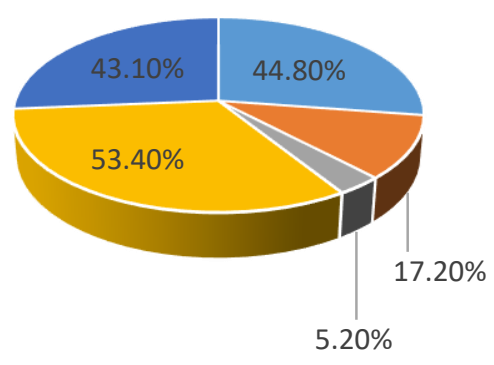

- a) Anxiety, agitation

•b) Insomnia

- c) Panic attacks

d) Boredom, monotony

- e) Dissatisfaction

As there can be seen, the most commonly mentioned reactions are boredom and monotony, restlessness and agitation and dissatisfaction.

For more than $60 \%$ of the subjects, the rules imposed by the state of lockdown caused them emotional discomfort to a large extent $(32.8 \%)$ and to an appropriate extent (32.8\%). Figure no. 3 shows the way in which the answers were distributed on the other variants as well. 
Figure no. 3. The opinion of the subjects regarding the emotional discomfort caused by the lockdown situation

\section{The opinion of the subjects regarding the emotional discomfort caused by the lockdown situation}

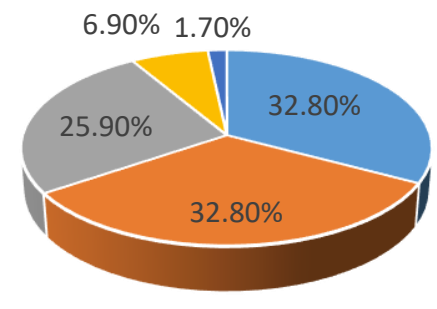

- a) To a large extent

- b) To an
appropriate extent
- c) To a small extent
- d) Not at all

- e) I can't appreciate

Item 7 was an open-ended one. Here are the most common states, negative emotions, that the subjects felt during the pandemic period:

- Anxiety, agitation, fear, boredom, confusion, depression, loneliness, high stress

- Lack of freedom, communication with colleagues, socializing, family events

- Social distancing, health care, certain restrictions.

- Emotional discomfort caused by noncompliance with covid protection rules at work

- Decreased ability to concentrate on courses

- Monotony, uselessness, agitation, panic platforms;

- Insufficient training in working on online

- Lack of direct interaction (face to face);

- Much higher volume of work in solving tasks;

- Reduction of attention, sedentarization, reduction of motivation

- Impossibility to practice outdoor recreation activities; the impossibility to go to the theater, opera, various events, etc ; the impossibility to interact face to face with many of the acquaintances, some of the teachers, colleagues, etc.

- Fear of getting sick and transmitting the disease to others.

As there can be seen from the answers provided by the students, they mentioned negative non-academic emotional reactions caused by the pandemic, but also academic states and emotions, determined by the need to carry out teaching activities online. The lack of interaction with their teachers and colleagues are also mentioned in the students' responses.

4b. In order to test the second hypothesis, we are presenting the results obtained in items 1, 6, 9 and 10 .

Thus, in item 1, the subjects appreciated to what extent the pandemic period affected their school activity. $43.1 \%$ of the subjects mentioned that this fact happened to a large extent, $27.6 \%$ - to a small extent, and $22.4 \%$ - to an appropriate extent. Only $6.9 \%$ thought that this period did not affect them.

Regarding the effects of online activity compared to the face to face one, the students mainly mentioned the ability to concentrate $(51.7 \%)$ and the emotional comfort (39.7\%). The complete answers of the subjects to this item can be viewed in figure no. 4 .

Figure no. 4. The students' assessments on the effects of online activity

The students' assessments on the effects of online activity

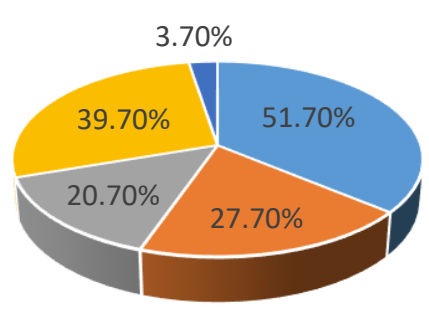

$$
\begin{aligned}
& \text { " a) Ability to } \\
& \text { concentrate } \\
& \text { - b) Memory capacity } \\
& \text { - c) Self-control, self- } \\
& \text { regulation } \\
& \text { " d) Emotional } \\
& \text { comfort } \\
& \text { - e) Self-esteem }
\end{aligned}
$$

To what extent the physical distance and the absence of interaction with teachers affected the school performance of the students, we can find out from the analysis of their answers to item no. 9. We are presenting, through figure no. 5, the way in which the answers to this item were distributed.

Figure no. 5. The subjects' responses to the effects of physical distance and teacher interaction on their school performance

The students' assessments on the effects of online activity

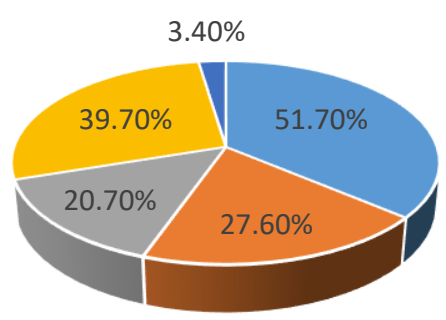
- a) Ability to concentrate
- b) Memory capacity
- c) Self-control, self- regulation
d) Emotional comfort
- e) Self-esteem 
As you can see, most answers are distributed on the first 3 answer options.

If regarding the lack of interaction with the teachers, the students appreciated that it influenced the school performance, in terms of the effects of the lack of interaction with the colleagues on the same performance, only $15.5 \%$ of the students mentioned that this was largely the case. $27.6 \%$ chose the "small" option and also $27.6 \%$ - the "not at all" option. The complete results are shown in figure no. 6 .

Figure no. 6. The subjects' opinion on the effects of lack of interaction with colleagues on school performance

\section{The subjects' opinion on the effects of lack of interaction with colleagues on school performance}

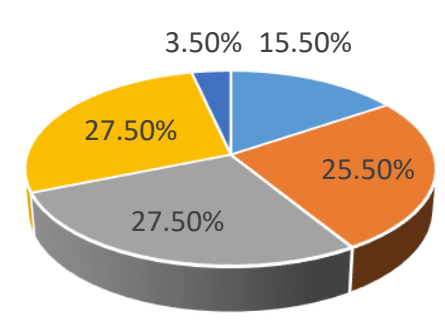

- a) To a large extent

- b) To an appropriate extent

- c) To a small extent

- d) Not at all

- e) I can't appreciate

4c. The last hypothesis of the research aimed at confirming the statement Awareness of the emotional states/reactions, as effects of isolation or distancing favor the possibility of identifying adaptive mechanisms/strategies, stress management.

In order to verify this statement, we are presenting the results obtained in items 4, 8, 11 and 12 .

Item 4 required the subjects to self-analyze the possibility of managing the emotional state caused by the pandemic. $37.9 \%$ appreciated that they largely managed this emotional state, and 43.8-to an appropriate extent. $10.3 \%$ chose the option - to a small extent, and $3.4 \%$ could not appreciate.

Item 8 was an open-ended one and it asked the students to mention 3 opportunities offered by the pandemic period. We are summarizing in the following, the most frequent answers:

- more time spent with the family

- more time for rest

- the possibility of doing pleasant, favorite, relaxing activities (for example, reading, watching movies or TV shows)
- understanding of how important people and socialization are

- easier and faster access to information and teaching materials, better attendance (participation) in courses

- diversity of information sources

- real-time information exchange

- improving digital skills

- taking exams in minimum stress conditions

- developing one's own projects, practicing several activities at the same time

- saving time spent on travelling

- financial savings, as a result of working at home.

There were also students who mentioned that they did not find the advantages or opportunities of this period.

The last 2 items of the questionnaire aimed at knowing the opinion of the subjects regarding the stressful character of the didactic activities carried out online, respectively of the exams carried out in the same way. If in the case of teaching activities, the opinions are relatively balanced on the first two answer options (Yes, they are less stressful - 41.4\% and No, they are not less stressful - 44.8\%), regarding the evaluation, $62.1 \%$ of the subjects consider that it is less stressful in the online version than face to face and only $34.5 \%$ say the opposite.

According to the results presented, we can consider that all the hypothetical statements made have proved their value in truth.

\section{Discussions}

The investigation we carried out aimed to find out the effects that the ongoing pandemic period has had, so far, on students, on their learning activity, on their school performance. We were able to make an inventory of the most common effects of the pandemic on the emotional state of the subjects, on their ability to concentrate, to remember. The answers of the students highlighted especially the psychological and behavioral reactions. In addition to highlighting the negative effects and consequences caused by the pandemic, some of the respondents also stressed the opportunities that the more time spent at home had. 
Also following the application of the opinion questionnaire, we were able to identify coping mechanisms and strategies, used in managing stressful situations, in reducing the negative effects of isolation, distancing, in finding ways to ensure their emotional comfort, well-being. For most of the subjects, stress management was done through their own mechanisms, without the need to call on people specializing in counseling or psychotherapy.

The results of the applied research tool confirmed our hypotheses, while providing relevant examples and concretizations. Viewed from the perspective of future teachers, the issue of effective stress management is even more important, given their basic role, perspective, that of trainer, personality educator of the future students, who must be trained in the spirit of this inner discipline and self-control, which reduces the harmful effects of potential stressors. Beyond the pandemic period we are going through, which has often potentiated the effects of stress, daily life, academic activity, it can itself be a source of stress. However, students-future teachers must learn to control the effects of stress or, possibly, to turn certain factors into sources of positive stress.

\section{Authors note:}

Florentina Mogonea, PhD Associate Professor, Teacher Training Department, University of Craiova, Director of the Psycho-pedagogical Research Center, Editor in-chief of the Academic Publication Annals of the University of Craiova, Psychology-Pedagogy series. Competence fields: Pre- and in-service training of teachers; theory and practice of school assessment; management and leadership of the class of students; educational research; sociology of education. The didactic and research activity has resulted in numerous publications and participations in national and international scientific events. Publications: 6 books being sole author; 5 methodological guides, auxiliaries for students, 2 coordinated books; 3 books published as co-author in international/national publishing houses; 13 books in collaboration; 20 studies published in the volumes "proceedings" of international conferences, indexed in international databases, 30 studies published in Romanian specialized journals. Participations in scientific events: 23 participations in international scientific events; 12 participations in national events.
Florentin Remus Mogonea, Associate Professor, Doctor of Education Sciences, Teacher Training Department, University of Craiova, permanent member of the Psycho-pedagogical Research Center, Editor of the Academic Publication Annals of the University of Craiova, Psychology-Pedagogy series. Competence fields: Pre- and in-service training of teachers; theory and practice of school assessment; management and leadership of the class of students; educational research; sociology of education. Publications: 5 volumes as sole author; 2 academic courses, manuals; 5 methodological guides, curriculum materials, tasks and tools, developed to support student's / teacher's learning; 1 books published in international publishing houses as coauthor; 23 chapters in books published in Romanian publishing houses; 1 coordinated volumes; 10 articles in extenso published in "proceedings" volumes with Peer-Review of ISI Thomson indexed Conferences. Participations in scientific events: participations in national (10) and international (16) scientific academic conferences (10); workshop coordinator in national (2) and international (2) conferences.

\section{References}

Liang, Z., Delvecchio, E. Buratta, L., \& Mazzeschi, C. (2020). "Ripple effect": Psychological responses and coping strategies of Italian children in different COVID19 severity areas. Revista de Psicología Clínica con Niños y Adolescentes, 7(3), 49-58. Available at: 10.21134/rpcna.2020.mon.2054 (accessed at 12.04.2021).

Chandra, Y. (2021). Online education during COVID-19: perception of academic stress and emotional intelligence coping strategies among college students. Asian Education and Development Studies, 10(2), 229-238. Available at: DOI 10.1108/AEDS-05-2020-0097 (accessed at 13.04.2021).

Field, K. (2020). 10 Tips to Support Students in a Stressful Shift to Online Learning. In The Chronicle of Higher Education, Coping with Coronavirus. How faculty members can support students in traumatic times, 8-11. Available at: https://wsac.wa.gov/sites/default/files/2020.03.24.Stude nt.Support.in.Traumatic.Times.pdf (accessed at 12.04.2021).

Baqutayan, S.M.S. (2015). Stress and Coping Mechanisms: A Historical Overview. Mediterranean Journal of Social Sciences, 6(2), 479-488. Available at: Doi:10.5901/mjss.2015.v6n2s1p479 (accessed at 12.04.2021). 
Mazo, G. N. (2015). Causes, Effects of Stress, and the Coping Mechanism of the Bachelor of Science in Information Technology Students in A Philippine University. Journal of Education and Learning, 9(1), 7178. Available

at: https://www.researchgate.net/publication/281761813_C auses_Effects_of_Stress_and_the_Coping_Mechanism_ of_the_Bachelor_of_Science_in_Information_Technolo gy_Students_in_a_Philippine_University/link/56425805 08aeacfd89382480/download (accessed at 12.04.2021).

Mariani, R. et. al. (2020). The Impact of Coping Strategies and Perceived Family Support on Depressive and Anxious Symptomatology During the Coronavirus Pandemic (COVID-19) Lockdown. Frontiers in Psychiatry, 11, 1-9. Available at: https://doi.org/10.3389/fpsyt.2020.587724 (accessed at 14.04.2021).

Al Dubai, S.A.R., Al Naggar, R.A., Al Shagga, M.A., Rampal, K.G. (2011). Stress and Coping Strategies of Students in a Medical Faculty in Malaysia. Malaysian Journal of Medical Science, 18(3), 57-64. Available at: https://www.researchgate.net/publication/215661236_St
ress_and_Coping_Strategies_of_Students_in_a_Medical _Faculty_in_Malaysia (accessed at 12.04.2021).

Kecojevic, A., Basch, C.H., Sullivan, M., Davi, N.K. (2020). The impact of the COVID-19 epidemic on mental health of undergraduate students in New Jersey, crosssectional study. PLOS ONE, 1-16. Available at: https://doi.org/10.1371/journal.pone.0239696, (accessed at 12.04.2021).

American Psychological Association. (2020). Coping with COVID-19-related Stress as a Student. Available at: https://www.apa.org/topics/covid-19/student-stress, (accessed at 15.04.2021).

Fink, G. (2017). Stress: Concepts, Definition and History. Reference Module in Neuroscience and Biobehavioral Psychology, 1-9. Available at: http://dx.doi.org/10.1016/B978-0-12-809324-5.02208-2 1 (accessed at 12.04.2021).

Shahsavarani, A.M., Abadi, E.A.M., Kalkhoran, M.H. (2015). Stress: Facts and Theories through Literature Review. International Journal of Medical Reviews, 2(2), 230-241. Available at: http://www.ijmedrev.com/article_68654_37adc02e9432 adfa017b8d6095cb6760.pdf (accessed at 15.04.2021). 